\title{
Performance Analysis of Wind Turbine Monitoring Mechanism Using Integrated Classification and Optimization Techniques
}

\author{
Dr. Subarna Shakya \\ Professor, Department of Electronics and Computer Engineering, \\ Central Campus, Institute of Engineering, Pulchowk, \\ Tribhuvan University, Nepal. \\ Email: drss@ioe.edu.np.
}

\begin{abstract}
The advanced improvements in the techniques utilized in the field of energy generation using the wind mills has led to the remarkable minimization in its capital investments and the cost incurred in its operation. This has even enhanced the prominence of the winds farms worldwide and has raised the market share of the energy produced using the wind mills. Thus leading to the increase in the necessity for capable monitoring mechanisms that is cost effective to report the conditions of the wind turbines regularly. So that it would be helpful in early diagnosis of any fault that has occurred in the wind turbines. To have an accurate monitoring and minimized maintenance cost the paper integrates the Support Vector machine based Cuckoo Search Algorithm. The incorporation of the SVM with the CSO is validated in MATLAB under the gain-factor and the fixed value types of faults that are liable to occur in the wind turbines and the results acquired are compared with the other existing methods such as the SVM-PSO and K-NN. The results observed shows that the SVM based CSO is more accurate in predicting the fault models than the other existing models.
\end{abstract}

Keywords: Wind Farms, Fault Diagnosis, Machine Learning Models, Cuckoo Search Optimization (CSO), Support Vector Machine (SVM), Particle Swarm Optimization (PSO), K-Nearest Neighbor.

\section{Introduction}

Encouraged by a portion of capital investment made by the public and the changes happening in the climate along with the speedy progress in the technology has paved way for the emergence of renewable energy sources in an enlarged ratio. Explicitly the energy generation through the wind farms have gained a high prominence worldwide, due to the lower capital investments and the operation cost incurred by involving the latest technologies in it. The wind farms are located either offshore or on shore and the energy gathered from them are collected in the turbines situated in the off shore or onshore respectively.

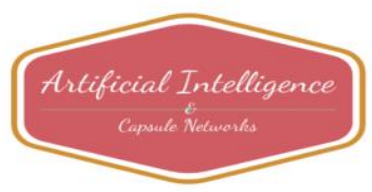


Journal of Artificial Intelligence and Capsule Networks (2020)

Vol.02/ No. 01

Pages: $31-41$

http://irojournals.com/aicn/

DOI: https://doi.org/10.36548/jaicn.2020.1.004

The energy produced through the wind farms have gained a high market value, so it becomes essential that these system are to be completely monitored throughout the year to have an early diagnose of faults and elude the failures in the wind mills and reduce the production level of the energy as well the profit attained in the market.

Monitoring of turbines in the wind farms is the process of observing thoroughly the operation as well as the maintenance. While the operations involves the complete management along with the control and the observance of the wind farms situated either in the off shore or the on shore, the maintenance takes care of the involvements that required to keep up the set up. The process of maintaining is further classified as "predictive, reactive or preventive" the figure. 1 below describes the different types of maintenance process involved in monitoring.
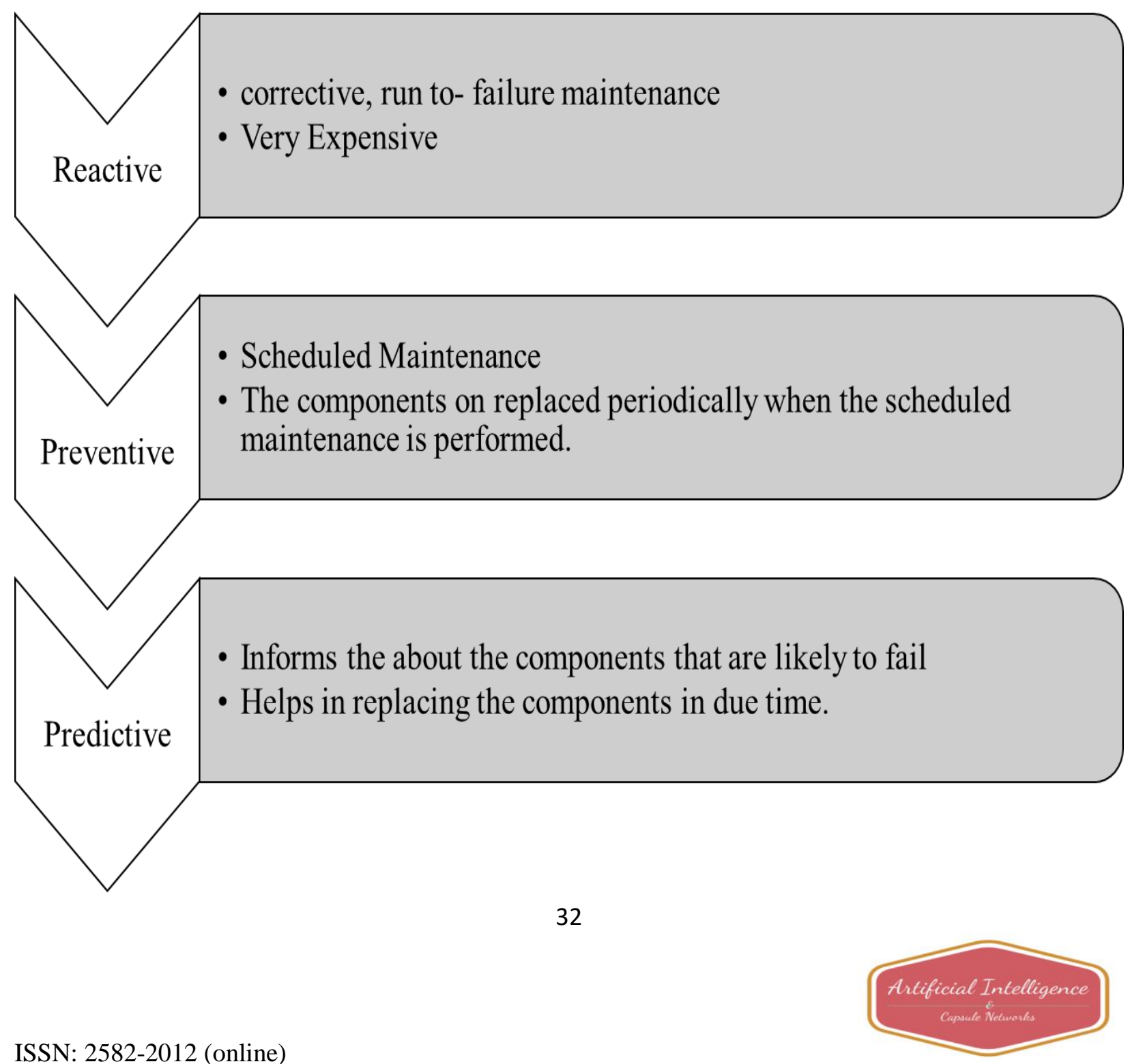
Journal of Artificial Intelligence and Capsule Networks (2020)

Vol.02/ No. 01

Pages: $31-41$

http://irojournals.com/aicn/

DOI: https://doi.org/10.36548/jaicn.2020.1.004

Figure. 1 Maintenance Process

The major types of monitoring are the "intrusive and the non-intrusive" and there monitoring is very helpful in detecting and predicting the occurrences of faults. The table. 1 below provides the details of the monitoring types and uses.

\begin{tabular}{|l|l|l|}
\hline Monitoring Types & Intrusive Monitoring & $\begin{array}{l}\text { involves Vibration Analysis } \\
\text { oil debris monitoring, shock } \\
\text { pulse methods etc. Such } \\
\text { methods impose a penalty } \\
\text { (wear) on the component } \\
\text { being monitored. }\end{array}$ \\
\cline { 2 - 3 } & Non-intrusive Monitoring & $\begin{array}{l}\text { involves ultrasonic testing } \\
\text { techniques, } \\
\text { visual inspection, acoustic } \\
\text { emission, thermography, } \\
\text { performance monitoring } \\
\text { using power signal analysis } \\
\text { etc. }\end{array}$ \\
\hline Monitoring Operations & Fault Detection & $\begin{array}{l}\text { Identifies the Faults } \\
\text { occurred }\end{array}$ \\
& Fault Prediction & $\begin{array}{l}\text { Finds patterns in the signal } \\
\text { data that are predictive of } \\
\text { failures in the future. }\end{array}$ \\
\cline { 2 - 4 } & &
\end{tabular}

Table.1 Monitoring Types and Operations

So to have an effective monitoring mechanism at a reduced cost the proposed method designs a monitoring mechanism that includes both the optimization and the classification techniques, while the optimization

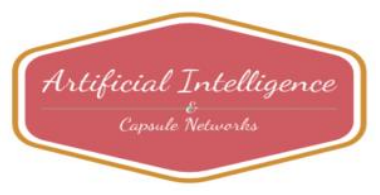


Journal of Artificial Intelligence and Capsule Networks (2020)

Vol.02/ No. 01

Pages: $31-41$

http://irojournals.com/aicn/

DOI: https://doi.org/10.36548/jaicn.2020.1.004

technique based on the cuckoo search is used in rectifying the "transmission expansion planning" the support vector machine based classification is utilized detection and the classification of the faults.

The mechanism put forth for the detecting as well as classifying faults, utilizes the CSO-SVM for the purpose of detection and classification. The method put forth can be subjected to reliable monitoring of the wind turbines as well as any of the machineries with rotating parts is systematized with the related works in the second section, the proposed optimization using the SVM and CSO in section three, the performance analysis in section four and the conclusion in section 5 .

\section{Related Works}

Wei, et al [1] presents the "Sensor fault diagnosis of wind turbines for fault tolerant." Zhou et al [2] presents the "A research on intelligent fault diagnosis of wind turbines based on ontology and FMECA" Blesa et al [3] has proposed the "Fault diagnosis of wind turbines using a set-membership approach." Taheri et al [4] has put forth the"Transmission network expansion planning under wind farm uncertainties using Cuckoo search algorithm." Gandomi, et al [5] has conducted the "Cuckoo search algorithm: a metaheuristic approach to solve structural optimization problems." Laouti et al [6] proposed a "Support vector machines for fault detection in wind turbines." Guangfei, et al [7] has devised an "Ice detection for wind turbine blades based on PSO-SVM method." Ranaee et al [8] devised an "Application of the PSO-SVM model for recognition of control chart patterns." Purarjomandlangrud et al [9] put forth the "Fault detection in wind turbine as a systematic literature review." Manikandan, $\mathrm{R}$ et al [10] performed a "Controller based performance measures of speed control of electrical motor for industrial applications." Joseph, S. Iwin et al [11] conducted a "Survey of data mining algorithms for intelligent computing system." Duraipandian, M et al [12] did a "Performance Evaluation of Routing Algorithm for Manet Based on the Machine Learning Techniques." Raj, Jennifer S et al [13] contributed "A Comprehensive Survey on the Computational Intelligence Techniques and Its Applications."

\section{Proposed Mechanism for Monitoring the Wind Turbines}

\subsection{Methodology Used}

(a) Support Vector Machine

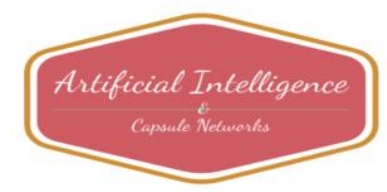


Journal of Artificial Intelligence and Capsule Networks (2020)

Vol.02/ No. 01

Pages: $31-41$

http://irojournals.com/aicn/

DOI: https://doi.org/10.36548/jaicn.2020.1.004

It is a method prominently used in the recognizing the pattern and also in process of classification. The algorithm mainly scopes in resolving the optimization problems. The hyper plane are used in the algorithm to segregate the linear, nonlinear and the kernel functions, and are very useful in distinguishing. The algorithm identifies the "isolation hyper plane in the feature space and categorizes the points in the space." The description of each function is tabulated in the table. 2 below.

\begin{tabular}{|l|l|}
\hline \multicolumn{1}{|c|}{ SVM Functions } & \multicolumn{1}{c|}{ Descriptions } \\
\hline Linear Function & $\begin{array}{l}\text { - It is dependable case and notified as ' } x_{i}^{\prime} \text { and } Y_{i} \\
\text { So the preparing set in the linear function are isolated by the } \\
\text { hyper plane with the margin represented as ' } \rho \text { ' at the point } \\
\text { from every case of } x_{i}^{\prime} \text { and } Y_{i}\end{array}$ \\
& $\begin{array}{l}\text { And for every support vector, there is supposed to be an } \\
\text { equality function that helps in acquiring the distance } \\
\text { between each support vector and the hyper plane }\end{array}$ \\
\hline Non-Linear Function & $\begin{array}{l}\text { Solves the dual problem formulation using the Kernel trick } \\
\text { dot product. Utilizing the dot product of the feature vectors, } \\
\text { is finished during the both the training and testing. }\end{array}$ \\
\hline Kernel Function & $\begin{array}{l}\text { Utilized for the non linear issue, } \\
\text { - It is the key technology of SVM theory } \\
\text { The parameters of the SVM decide both the learning and } \\
\text { generalization capability } \\
\text { The two major RBF parameters connected in the SVM } \\
\text { where one is used to regulates the equilibrium between the } \\
\text { complexity of the model and the exact error and the other } \\
\text { parameter is a flexible parameter. }\end{array}$ \\
\hline
\end{tabular}

Table.2 Functions of SVM

As majority of the parameters of the SVM were decided by the intelligent algorithm. The proposed mechanism utilizes the SVM to distinguish the faulty operations and the parameters of the SVM are optimized using the CSO.

\section{(b) Cuckoo Search Algorithm}

The algorithm that relies on the probability of cuckoo in hatching its own eggs is used in the proposed method to decide the SVM parameters. The general description of the technique is as follows. The cuckoo

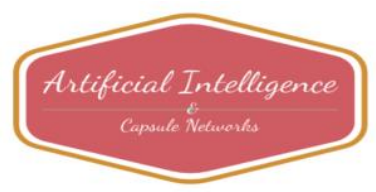


Journal of Artificial Intelligence and Capsule Networks (2020)

Vol.02/ No. 01

Pages: $31-41$

http://irojournals.com/aicn/

DOI: https://doi.org/10.36548/jaicn.2020.1.004

lays its eggs randomly in any nest that belongs to the other birds and the eggs with the higher fitness hatches. Based on this above mentioned the CSO locates the search path and searches for the highest fittest eggs in the nests of the host. The two parameters of the CSO are ' $\mathrm{M}$ ' and ' $\mathrm{P}$ ' were the $\mathrm{M}$ is constant and the ' $\mathrm{P}$ ' regulates the balance across the search that is random and local.

\section{(C) Proposed Algorithm}

The flowchart in the figure. 2 describes the phases in the optimization of the SVM parameters using the Cuckoo Search Algorithm.

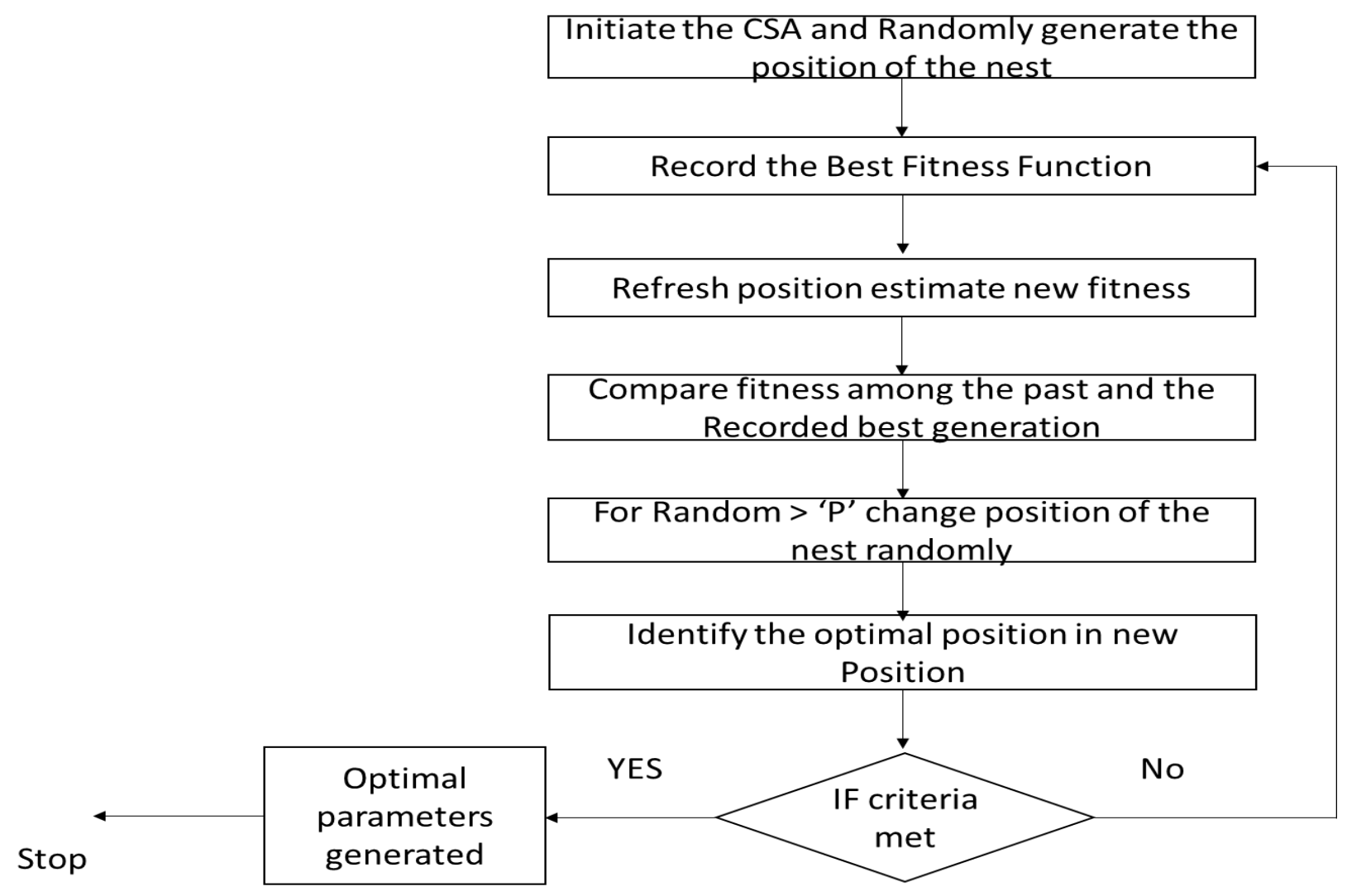

Figure. 2 SVM Parameters Optimization Using CSO 
Journal of Artificial Intelligence and Capsule Networks (2020)

Vol.02/ No. 01

Pages: $31-41$

http://irojournals.com/aicn/

DOI: https://doi.org/10.36548/jaicn.2020.1.004

\section{Performance Analysis}

The simulation of the proffered method was performed in the MATLAB under two main types of faults as listed in table. 3 The sensors lays as the fundamental devices in monitoring the operations of the Wind turbines.

\begin{tabular}{|c|c|}
\hline Fault Type & Fault Size \\
\hline Fixed Value & Sensor Fault Blade Position \\
\hline Gain Value & Sensor Fault Blade Position \\
\hline Fixed Value & Sensor Fault Rotor Speed \\
\hline Gain Value & Sensor Fault Rotor Speed \\
\hline Fixed Value & Sensor Fault Generator Speed \\
\hline Gain Value & Sensor Fault Generator Speed \\
\hline
\end{tabular}

Table.3 Types of Faults

The table. 4 below demonstrates the "APE and the RMSE" value obtained by the SVM based CSO and the other existing algorithms such as the SVM with PSO and the KNN where the APE-absolute percent error and the RMSE-root mean square error are estimated using the following equations 1 and 2

\begin{tabular}{|c|c|c|}
\hline Models & APE \% & RMSE\% \\
\hline CSO-SVM & .136 & .3 \\
\hline PSO-SVM & .191 & .4 \\
\hline KNN & .190 & .4 \\
\hline
\end{tabular}


Journal of Artificial Intelligence and Capsule Networks (2020)

Vol.02/ No. 01

Pages: $31-41$

http://irojournals.com/aicn/

DOI: https://doi.org/10.36548/jaicn.2020.1.004

Table.4 Absolute Percent Error and Root Mean Square Error

$$
\begin{array}{r}
A P E=\sum_{i=1}^{n} \bmod \left(X(i)-X^{i}\right) / n \\
R M S E=\sum_{i=1}^{n} \operatorname{sqrt}\left(\left(X(i)-X^{i}\right) / n\right)
\end{array}
$$

While $X(i)=$ "actual value" and the $X^{i}=$ "modeling value" and' $n$ ' is the testing samples

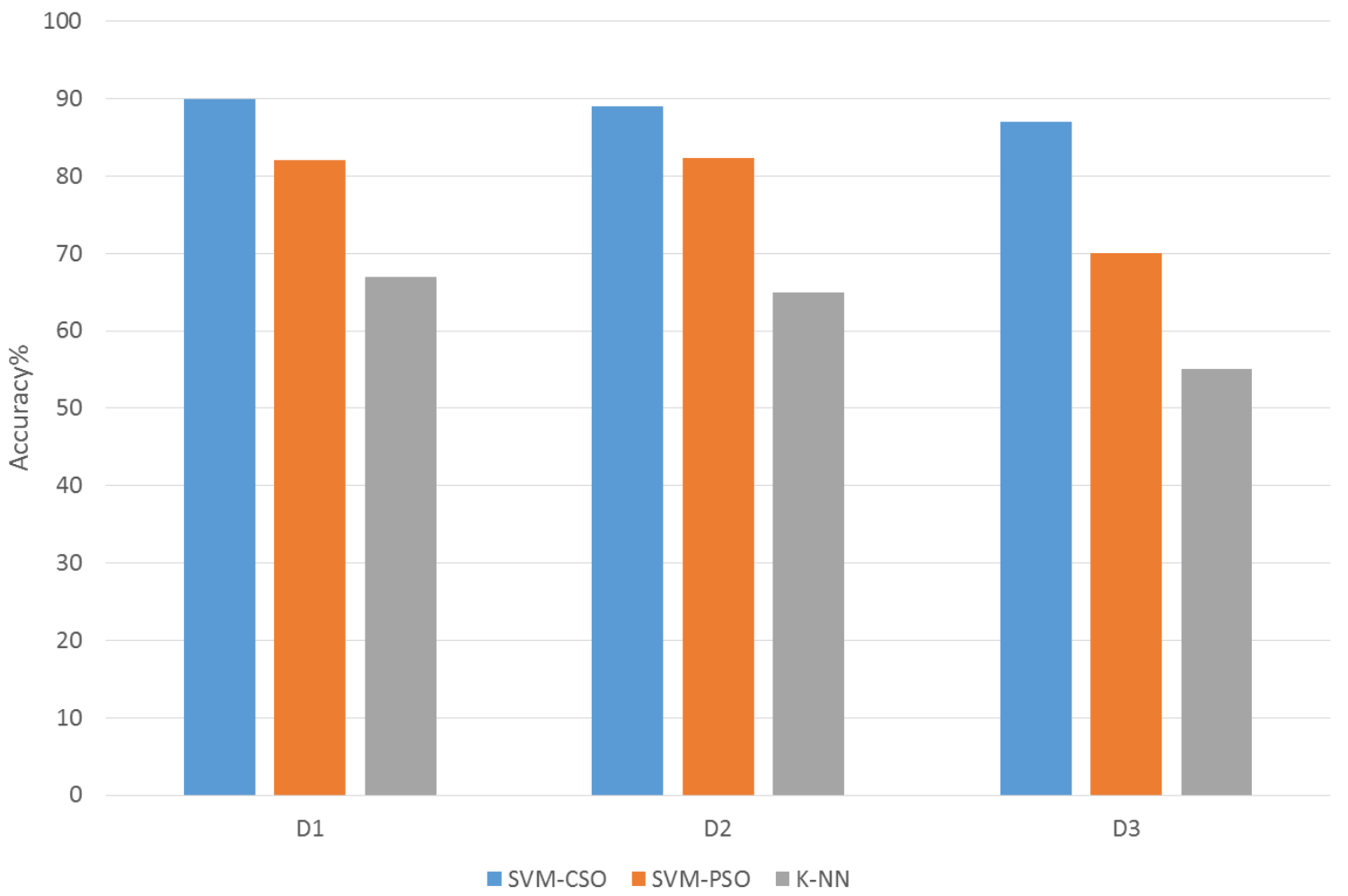

Figure.3 Accuracy in classification

The accuracy of the models "CSO-SVM, SVM-PSO and KNN" is depicted below in the figure. 3 the accuracy of the models observed shows that the proposed method has a higher accuracy compared to the

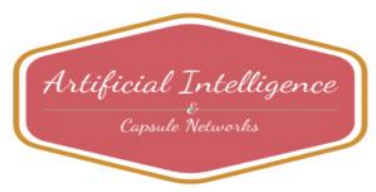


Journal of Artificial Intelligence and Capsule Networks (2020)

Vol.02/ No. 01

Pages: $31-41$

http://irojournals.com/aicn/

DOI: https://doi.org/10.36548/jaicn.2020.1.004

other two methods on different data sets (D1, D2,D3) that was obtained from the signal data's on different duration.

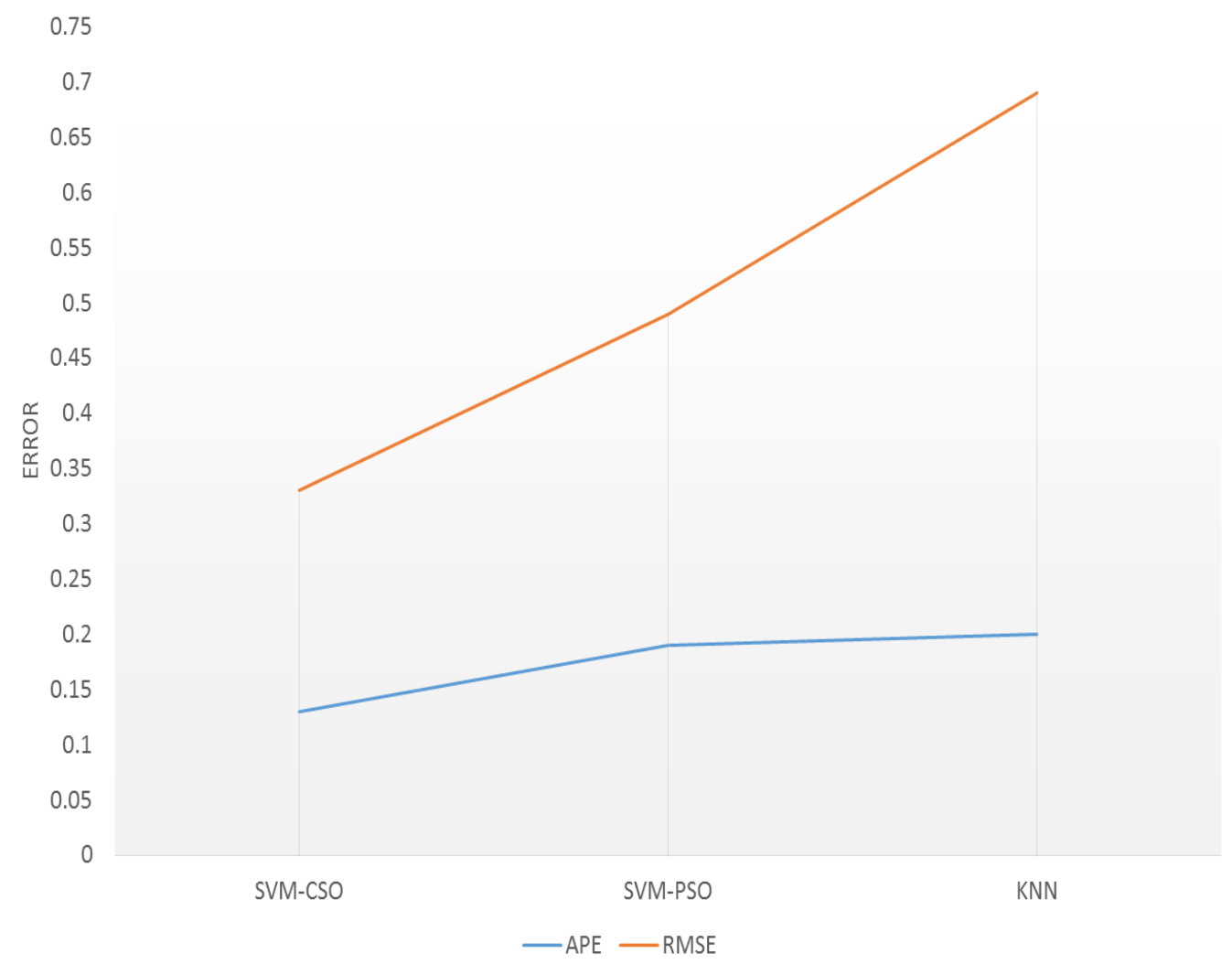

Figure. 4 Error Observed

The figure. 4 presents the total error observed on all the three methods based on the absolute percent error and the root mean square error estimated for the each model based on the equation 1 and 2 . The above mentioned errors were utilized as the state feature combination and the training set was formed with the 200 signal data's that had 100 set with thirteen different kinds of operation under a normal state and 50 on damaged circumstances and 50 on other stat of operations. The training set were taken randomly and the rest of the data were used as the test set based on the data set provided all the three models were evaluated and the recognition rate of the CSO-SVM outperformed the other two.

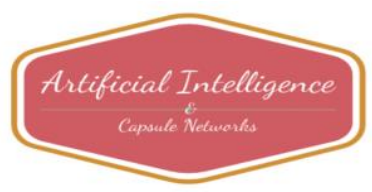


Journal of Artificial Intelligence and Capsule Networks (2020)

Vol.02/ No. 01

Pages: $31-41$

http://irojournals.com/aicn/

DOI: https://doi.org/10.36548/jaicn.2020.1.004

\section{Conclusion}

To monitor the conditions of the turbine of the wind mills the paper formulates the SVM based fault identification with its parameters selected using the CSO. The optimal parameters were selected based on CSO and the novel method to deal the failures in the wind turbines was devised. The proposed method proved to provide an effective way of fault identification at minimum cost. The method further proves to minimize the maintenance cost as well by saving the components prior to the occurrence of the intensive faults. The accuracy of the method and the error rate of the method were considerably low compared to the existing methodologies.

\section{References}

[1] Wei, Xiukun, Michel Verhaegen, and T. Van den Engelen. "Sensor fault diagnosis of wind turbines for fault tolerant." IFAC Proceedings Volumes 41, no. 2 (2008): 3222-3227.

[2] Zhou, Anmei, Dejie Yu, and Wenyi Zhang. "A research on intelligent fault diagnosis of wind turbines based on ontology and FMECA." Advanced Engineering Informatics 29, no. 1 (2015): 115-125.

[3] Blesa, Joaquim, Vicenç Puig, Juli Romera, and Jordi Saludes. "Fault diagnosis of wind turbines using a set-membership approach." In Proceedings of IFAC world congress, pp. 8316-8321. 2011.

[4] Taheri, S. Saeid, S. Jalal Seyed-Shenava, and M. Modiri-Delshad. "Transmission network expansion planning under wind farm uncertainties using Cuckoo search algorithm." (2014): 28-6.

[5] Gandomi, Amir Hossein, Xin-She Yang, and Amir Hossein Alavi. "Cuckoo search algorithm: a metaheuristic approach to solve structural optimization problems." Engineering with computers 29, no. 1 (2013): 17-35.

[6] Laouti, Nassim, Nida Sheibat-Othman, and Sami Othman. "Support vector machines for fault detection in wind turbines." IFAC Proceedings Volumes 44, no. 1 (2011): 7067-7072.

40

ISSN: 2582-2012 (online)

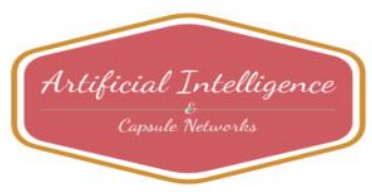


Journal of Artificial Intelligence and Capsule Networks (2020)

Vol.02/ No. 01

Pages: $31-41$

http://irojournals.com/aicn/

DOI: https://doi.org/10.36548/jaicn.2020.1.004

[7] Guangfei, Zhou, Tan Wen, and Zhang Da. "Ice detection for wind turbine blades based on PSOSVM method." In Journal of Physics: Conference Series, vol. 1087, no. 2, p. 022036. IOP Publishing, 2018.

[8] Ranaee, Vahid, Ata Ebrahimzadeh, and Reza Ghaderi. "Application of the PSO-SVM model for recognition of control chart patterns." ISA transactions 49, no. 4 (2010): 577-586.

[9] Purarjomandlangrudi, Afrooz, Ghavameddin Nourbakhsh, Mohammad Esmalifalak, and Andy Tan. "Fault detection in wind turbine: a systematic literature review." Wind engineering 37, no. 5 (2013): 535-547.

[10] Manikandan, R., and S. Smys. "Controller based performance measures of speed control of electrical motor for industrial applications." In 2017 International Conference on Inventive Systems and Control (ICISC), pp. 1-5. IEEE, 2017.

[11] Joseph, S. Iwin Thanakumar, and Iwin Thanakumar. "Survey of data mining algorithm's for intelligent computing system." Journal of trends in Computer Science and Smart technology (TCSST) 1, no. 01 (2019): 14-24.

[12] Duraipandian, M. "PERFORMANCE EVALUATION OF ROUTING ALGORITHM FOR MANET BASED ON THE MACHINE LEARNING TECHNIQUES." Journal of trends in Computer Science and Smart technology (TCSST) 1, no. 01 (2019): 25-38.

[13] Raj, Jennifer S. "A COMPREHENSIVE SURVEY ON THE COMPUTATIONAL INTELLIGENCE TECHNIQUES AND ITS APPLICATIONS." Journal of ISMAC 1, no. 03 (2019): 147-159.

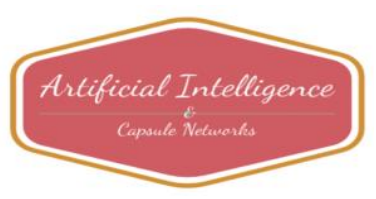

